\title{
Economic role of education in agriculture: evidence from rural Vietnam
}

\author{
Le Khuong Ninh \\ Can Tho University, Can Tho, Viet Nam
}

Economic role of education in agriculture

\begin{abstract}
Purpose - This paper investigates the impact of education on output of rice farming households in Vietnam. Design/methodology/approach - Given the literature review, this paper specifies three empirical models (i.e. linear constant coefficient model, partially nonlinear model and linear varied coefficient model) with variables that well describe the mechanism through which education affects output. The data were collected from 901 rice farming households randomly selected out of ten provinces and city in the Mekong River Delta (MRD) of Vietnam. The models are estimated using ordinary least squares (OLS) and Robinson's (1988) double residual estimators.

Findings - Estimates of the empirical models show that seed, fertilizer, labor and farm size have significant impacts on output of rice farming households while pesticide and herbicide do not. Education is also found to have a positive effect on output of rice farming households because it helps them better manage farms of larger size via combining various inputs in a more desirable way.

Originality/value - This paper confirms the positive impact of education on agricultural output, which implies that policies aiming to provide better education to rural people will greatly enhance their income as well as trigger long-term economic and agricultural growth.
\end{abstract}

Keywords Agriculture, Education, Household, Input, Output, Rice, Rural, Schooling, Vietnam

Paper type Research paper

\section{Introduction}

People very much appreciate education since it enables them to behave decently and respond wisely to uncertain economic and social incidents. Therefore, many households in rural areas of developing countries have deliberately devoted an enormous portion of their income and scarce resources to attaining good education. Consequently, the role that education plays in economic and agricultural growth has been allured a due attention in the literature. Researchers have inclined to include education attainment as an explicit determinant of agricultural output (e.g. Vollrath, 2007; Asadullah and Rahman, 2009; Reimers and Klasen, 2013; Wouterse, 2016; Wouterse and Badian, 2019). Yet, if better educated farmers are adept at making production decisions, accessing relevant information, adopting new technologies and judging inputs, then it remains questionable why empirical studies have not always identified a positive impact of education on agricultural output. Perhaps, the literature is inconclusive about that role of education since empirical models with inadequate variables or inappropriate econometric methods may have been used to estimate the impact.

That education yields positive returns from agricultural production remains an open issue in Vietnam since it has been overlooked. If one can prove a positive role of education to agricultural output, it is worthwhile raising investment to enhance opportunities for people to attend classes and to improve school quality. In other words, such a role of education would mean that there is a value of allocating a greater deal of resources to promote education, thus

(C) Le Khuong Ninh. Published in Journal of Economics and Development. Published by Emerald Publishing Limited. This article is published under the Creative Commons Attribution (CC BY 4.0) license. Anyone may reproduce, distribute, translate and create derivative works of this article (for both commercial and non-commercial purposes), subject to full attribution to the original publication and authors. The full terms of this license may be seen at http://creativecommons.org/licences/by/4.0/legalcode

Received 1 May 2020 Revised 11 August 2020 31 August 2020

Accepted 31 August 2020$$
\text { (1) }
$$ 
JED

23,1

48

boosting long-term economic and agricultural growth. Therefore, this paper aims to shed light on the impact of education on agricultural output, using a primary dataset collected from 901 rice farming households randomly selected out of ten provinces and city in the Mekong River Delta (MRD) - the rice bowl that accounts for more than half of rice output of Vietnam. The novelty of this paper is to confirm the positive role of education to rice output by showing the stronger effect of education on rice output of farms of larger sizes.

This paper proceeds as follows. Section 2 reviews the literature on the impact of education on agricultural output. Section 3 specifies the empirical models and the estimation strategy used to estimate the models. The dataset employed to test the impact of education on output of rice farming households is discussed in Section 4. Section 5 describes Vietnam's education system. Section 6 presents the empirical results. Section 7 concludes the paper.

\section{Literature review}

As popularly agreed, education has a positive impact on agricultural output. A number of mechanisms through which education influences agricultural output have been explored by researchers. Education boosts farmers' ability to obtain, decode and understand information, thus enabling them to make better use of available information to come up with pertinent solutions to production, market and financing challenges. In other words, farmers with good education possess improved decision-making skills and hence better manage resources to exploit farms of various sizes (Asadullah and Rahman, 2009). Well-educated farmers are not only capable of utilizing available information but also better access to needed information, implying that education alleviates information asymmetry in a number of aspects, especially regarding input quality which is vital to agricultural output. Consequently, highly educated farmers use a combination of inputs superior to what is applied by low-skilled ones, meaning that the former allocates scarce resources more efficiently (Reimers and Klasen, 2013).

Various studies have divulged that better educated farmers are more active in adopting new technologies, thereby enjoying the first-mover advantage (Lin, 1991; Asfaw and Admassie, 2004; Weir and Knight, 2004). Well-educated farmers are likely to adopt new technologies early since they get distinct access to relevant information and are capable of distinguishing between promising and unpromising innovations. By contrast, farmers with limited education often prefer not to take up a new technology until its benefits have been proved or wait till their counterparts have successfully applied it, providing educated farmers with a first-mover advantage and making the new technology even more profitable and attractive. Educated farmers adopt new technologies earlier since they are more willing to embrace riskier production technologies of higher expected returns (Knight et al., 2003; Asadullah and Rahman, 2009). Hence, education is supposed to reduce the perceived level of uncertainty and the aversion of the farmer toward endogenous risks arising from his own choice of production technology. This means that providing education to a farmer may encourage him to take up new technologies earlier and also alters their attitude towards risky production technologies (e.g. crops or varieties they have not dared to plant previously). The farmer then optimizes his mix of inputs to nurture crops based on the improved ability to evaluate the associated risks and opportunities thanks to the education attained. Education may raise the value of farmers' entrepreneurial ability - the ability to perceive, interpret and respond to new events in the context of risk. This happens when, for the same amount of inputs, different magnitudes of output are obtained by following distinct methods of input combination (Croppenstedt and Demele, 1997).

When considering the role of education to agricultural output, it is useful to distinguish between cognitive and non-cognitive effects (Taylor and Yunez-Naude, 2000). Regarding the cognitive effect, one can be aware of the formation of general skills like literacy and numeracy. Literacy as an indispensable element of education enables a farmer to follow 
written instructions as to chemical input usage. Numeracy warrants him to calculate precise dosages and facilitates the making of wise production decisions. Consequently, the cognitive effect of education raises output given a certain amount of inputs. Education also has a noncognitive effect that changes farmers' attitudes and preferences with respect to the utilization of inputs, especially hired labors who are normally prone to moral hazard since wages are often predetermined while their work effort is not be fully observable, verifiable and enforceable due to information asymmetry (Foster and Rosenzweig, 1994; DeSilva et al., 2006). As such, education improves the allocative efficiency via the greater propensity to select inputs of higher productivity.

As previously explained, education improves decision-making skills of farmers. In their farms, farmers apply a combination of conventional inputs that have to be well managed since any misuse of them is very costly (especially for households of poor endowment) and may have adverse effects on output and thus income. In liberalized factor markets, many private input suppliers are active. Thus, there are several potential sources of market failure in the provision of agricultural inputs while relevant regulations may be loose. There are basically two types of imperfect information related to agricultural input use, which gives rise to market failure. The first concerns input quality. For instance, the effect of fertilizer application is often not seen for a couple of months. It is thus quite feasible for unscrupulous traders to market inferior quality products. The second has to do with improper knowledge of farmers that make input uses sub-optimal or even ineffective in a number of cases. Another problem facing farmers regards seed quality. Seed certification should be done by the public sector although it can be performed by private organizations. However, the government may fail to regulate seed testing, so private input suppliers try to create a good image for themselves by applying own inadequate seed testing procedures as well as giving advices to farmers. Consequently, there is a high degree of information asymmetry for farmers with respect to the use of inputs for production. The larger the farm size is, the bigger quantity of inputs will be used, so it is harder to combine them in a right way due to the aforementioned defects. In that case, education-induced knowledge and skills help enable farmers to determine better combination of inputs as their quantity gets larger in accordance with farm size.

\section{Empirical model specification and estimation strategy}

The mechanism through which education influences agricultural output can be examined based on a production model of a farmer producing a commodity using conventional inputs. A common linear version of a constant coefficient Cobb-Douglas production function shows a farmer transforming conventional inputs into output:

$$
y_{i}=\beta_{0}+\beta_{S} \operatorname{seed}_{i}+\beta_{F} \text { fertilizer }_{i}+\beta_{P} \text { pesticide }_{i}+\beta_{H} \text { herbicide }_{i}+\beta_{L} \text { labor }_{i}+\varepsilon_{i}
$$

where the dependent variable $\left(y_{i}\right)$ is natural logarithm $(\log )$ of output of farmer $i$ and the independent variables are log of inputs used by that farmer. Therefore, the coefficients (i.e. $\beta_{S}, \beta_{F}, \beta_{P}, \beta_{H}$, and $\beta_{L}$ ) are the elasticities of output with respect to each input.

As theoretically explained, education $\left(\mathrm{edu}_{i}\right)$ - proxied by the number of schooling years (Barro and Lee, 2010) - affects output of the farmer via a number of mechanisms, so we expect a significant and positive relationship between $y_{i}$ and $e d u_{i}$ such that $d y_{i} / d\left(\mathrm{edu}_{i}\right)>0$. This nexus can be studied by examining if edu $u_{i}$ enhances output $\left(y_{i}\right)$ after controlling for inputs and farm size (farmsize $)_{i}$ - an important determinant of agricultural output (Barrett et al., 2010; Larson et al., 2014; Ali and Deininger, 2015; Sheng et al., 2019; Muyanga and Jayne, 2019) - as in a linear version of a constant coefficient Cobb-Douglas function parametrically augmented with the education variable $\left(\mathrm{edu}_{i}\right)$ :
Economic role of education in agriculture 
JED

23,1

$$
\begin{aligned}
y_{i}= & \beta_{0}+\beta_{S} \operatorname{seed}_{i}+\beta_{F} \text { fertilizer }_{i}+\beta_{P} \text { pesticide }_{i}+\beta_{H} \text { herbicide }_{i}+\beta_{L} \text { labor }_{i} \\
& +\beta_{M} \text { farmsize }_{i}+\beta_{E} \text { edu }_{i}+\varepsilon_{i}
\end{aligned}
$$

A drawback of a parametric specification of a production function is that the estimated result is sensitive to the functional form chosen, giving rise to imprecise conclusions. Since previous studies have got no consensus about the relationship between farm size and output (Deininger and Byerlee, 2012; Sheng et al., 2019; Muyanga and Jayne, 2019), we need to empirically establish an appropriate partially nonlinear model regarding farm size (farmsize ${ }_{i}$ ). To do so, we utilize a partially nonlinear regression model proposed in Robinson (1988):

$$
\begin{aligned}
y_{i}= & \beta_{0}+\beta_{S} \text { seed }_{i}+\beta_{F} \text { fertilizer }_{i}+\beta_{P} \text { pesticide }_{i}+\beta_{H} \text { herbicide }_{i}+\beta_{L} \text { labor }_{i} \\
& +\beta_{M}\left(\text { farmsize }_{i}\right)+\beta_{E} \text { edu }_{i}+\varepsilon_{i}
\end{aligned}
$$

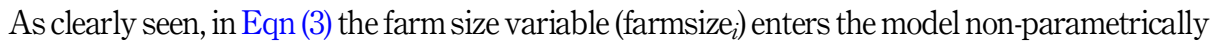
since its functional form is not specified in advance. The non-parametric approach to estimating production functions introduced by Afriat (1972) and Varian (1984) has its obvious advantage of not imposing any a priori restrictions on the underlying production technology, therefore avoiding the risk of incorrect estimation method and conclusion in the case of model misspecification. Eqn (3) can be estimated using Robinson's (1988) double residual estimator.

Using regression models with constant coefficients, like Eqs (2) and (3), in production economics is quite popular. This approach means that independent variables do not significantly differ in their behavior from one observation to another (e.g. farmer). This may be flawed since production possibilities are in fact expected to vary in a cross-section of farmers as different technologies utilized by them may coexist at any given time, especially regarding farmers with various education attainments. Hence, it is needed to apply parameter variation across farmers as specified by Hildreth and Houck (1968), Swamy and Tavlas (1995). In other words, constant coefficient production functions describing a production technology common to all farmers may not adequately reflect the reality. To tackle the problem, we let the coefficient of farm size variable (farmsize ${ }_{i}$ ) vary with the farmer's education $\left(\mathrm{edu}_{i}\right)$ and expect that $\partial^{2} y_{i} / \partial\left(\right.$ farmsize $\left._{i}\right) \partial\left(\mathrm{edu}_{i}\right)>0$, as in the following production function with cross (interaction) term (i.e. farmsize ${ }_{i} \times$ edu $_{i}$ ):

$$
\begin{aligned}
y_{i}= & \beta_{0}+\beta_{S} \text { seed }_{i}+\beta_{F} \text { fertilizer }_{i}+\beta_{P} \text { pesticide }_{i}+\beta_{H} \text { herbicide }_{i}+\beta_{L} \text { labor }_{i} \\
& +\beta_{M} \text { farmsize }_{i}+\beta_{E} \text { edu }_{i}+\beta_{M E} \text { farmsize } \times \text { edu }_{i}+\varepsilon_{i}
\end{aligned}
$$

or a partially nonlinear regression model:

$$
\begin{aligned}
y_{i}= & \beta_{0}+\beta_{S} \operatorname{seed}_{i}+\beta_{F} \text { fertilizer }_{i}+\beta_{P} \text { pesticide }_{i}+\beta_{H} \text { herbicide }_{i}+\beta_{L} \text { labor }_{i} \\
& +\beta_{M}\left(\text { farmsize }_{i}\right)+\beta_{E} \text { edu }_{i}+\beta_{M E} \text { farmsize } \times \text { edu }_{i}+\varepsilon_{i}
\end{aligned}
$$

In Eqs (4) and (5), we interact the education variable (edu $\left.{ }_{i}\right)$ with the farm size variable (farmsize ${ }_{i}$ ) so as to examine the impact of education on output via better production decisions over farms with a bigger size where a larger quantity of conventional inputs is applied. Again, Eqn (4) is estimated by ordinary least squares (OLS) estimator and Eqn (5) is estimated using Robinson's (1988) double residual estimator.

\section{Data and variable measurement}

The data used in this paper were collected via direct interviews with heads of 901 rice farming households randomly selected out of ten provinces and city in the MRD of Vietnam. In each province (city), the village with the largest area of land devoted to rice production from the 
district with the largest area of land devoted to rice production was picked up for survey. In each village, 200 rice farming households were randomly chosen for interview. Questionnaires were directly administered through face-to-face interviews with household heads. Yet, due to difficulties in reaching household heads, being refused by informants and missing information on relevant aspects, we are able to create a primary dataset of just 901 rice farming households. The data obtained include output and educational attainment of household heads, together with input costs incurred by the farming households and other additional attributes.

In this paper, we use self-reported information on output provided by household heads. Researchers (e.g. Bhalla and Roy, 1988; Escobal and Laszlo, 2008; Carletto et al., 2013) have argued that self-reported data may be subject to measurement errors since the informants may exaggerate figures. However, in the case of rice farming households in the MRD, this may not be a problem since most of them sell their produce immediately after harvest directly to brokers or traders who deliberately weigh the rice very carefully so as to avoid disadvantages. Thus, the figure on rice output reported by the households is precise to a certain extent.

As to education, we follow Barro and Lee (2010) to use the number of schooling years to account for educational attainment of household heads since this criterion contains the stock of knowledge pertaining to production decisions made by household heads so as to maximize output. Measuring the amount of inputs used by households in rice production is a bit complicated since each of them uses a number of different types of inputs to take care of rice plants, which does not allow us to just add their quantity up. To get rid of the problem, we use the market price in 2018 of each type of the inputs to create the cost (or value) of inputs used in rice production. To be concrete, in order to measure the cost of inputs to use it as a proxy for the amount of inputs applied by the rice farming household, we first multiply the quantity of each type of input by its price and then adding the values together.

\section{Vietnam's education system}

Vietnam's education system comprises elementary schools, secondary schools, high schools, vocational schools, junior colleges and universities. Elementary education in Vietnam starts at the age of six and lasts five years (from grade 1 to grade 5). Subjects taught in elementary schools consist of Vietnamese, mathematics, moral education, natural and social sciences, arts, physical education, as well as history and geography in grades 4 and 5 . The curriculum emphasizes rote memorization. After completing grade 5, pupils can go on with secondary education for four years (from grade 6 to grade 9 ) or enroll in short-term vocational training programs. The curriculum is about Vietnamese, foreign languages, mathematics, natural sciences, civics, history, geography, technology, computer science, arts and physical education.

Access to high schools in Vietnam is competitive and examination-based. Students who do not score sufficiently in entrance exams to be admitted into high schools in the general track may look for chances in vocational programs or go to costly private schools. High education runs for three years (from grade 10 to grade 12). Programs are offered in three different streams or subject groups, including technology, natural sciences, social sciences and foreign languages. Reforms enacted in 2017 allowed for greater individual customization with elective concentration subjects that make up a third of the curriculum. High school graduation requires passing a rigorous final graduation examination, which is also used to get admission to higher education.

Several options for vocational education are available in Vietnam, ranging from short-term continuing education programs to formal training program at both secondary and high education levels. Short-term vocational certificate program offered at vocational training centers are open to elementary school graduates, whereas longer programs (up to three years) offered at vocational schools require completion of at least secondary education for admission. These longer programs conclude with the award of a Vocational Training Diploma, which can
Economic role of education in agriculture 
JED

23,1

52

be used to get employed in a number of trades. Secondary graduates can also enroll in more vocationally or technically oriented high schools, referred to as professional high education which combine vocational training with general education. These programs which last three to four years and usually require passing an entrance examination lead to the award of a Professional High Education Graduation Diploma. Passing the final vocational high school graduation examination upon completion of the program gives access to higher education, but most students in the vocational track go on with junior colleges. Vocational high education is typically provided at junior colleges although college-level programs are increasingly offered by universities. The programs are geared towards employment, with fields of study being business administration, banking, accounting, tourism, information technology or health care. Admission is based on the high school graduation examination.

Progression from high schools to higher education in Vietnam is highly competitive and based on demanding examinations. Since 2015, the university entrance exam has been cancelled and integrated with the high education graduation examination into a single national high school graduation examination, now used to get university admission. Students in rural areas can now take the exam locally instead of going to towns where universities are located. Although there has been a growing number of new universities, Vietnam's higher education system does not sufficiently meet the demand of the burgeoning youth population as it has had capacity for a third of applicants. The fast-paced growth of the education system has intensified quality problems of overcrowded universities and led to the mushrooming of low-quality private universities. Vietnam has been a dynamic outbound student markets worldwide due to the shortcomings of its education system which are featured by international isolation, a lack of high-quality universities, inadequate foreign language training, bureaucratic obstacles and weak curricula that do not prepare students for entry into the labor force.

As just described, in the early stage of education students in Vietnam are provided with merely basic knowledge mainly through rote memorization of a limited number of subjects. Higher levels of education with an expanded range of subjects, in which more active learning replaces one-way lecturing and rote memorization, allow students to learn advanced knowledge that nurtures the capacity of problem-solving, critical thinking, communicating and working in team, albeit still imperfect so far. Skills gradually obtained via education, i.e. cognitive, social, behavior and technical skills, enable students to better seek, access and utilize relevant information about concerned aspects of work and lives, making them more agile and adept in adopting new technologies that are vital to the success of production (e.g. farming) of larger scales which are harder to be managed. As a matter of fact, the education system in Vietnam has been improved on a number of features, e.g. access, quality, efficiency and equity, but rural students and labors may to a certain extent remain in a desperately disadvantageous condition compared with their urban counterparts due to inadequate public awareness and investment (Pham and Tran, 2015). Therefore, agricultural labors can be characterized by relatively poor education attainment and thus be able to engage in jobs on seasonal basis, which bring about low annual incomes (Brunjes and Diez, 2016). In spite of that fact, like what was argued by Fielke and Bardsley (2014), higher levels of education certainly contribute to famers being better able to enhance outcomes of their agricultural land use and more adaptive in a liberalized economy (including Vietnam).

\section{Results}

\subsection{Sample description}

The sample includes 901 rice farming households randomly selected out of ten provinces and city of the MRD. The average age of household heads is 51.56, with a SD of 10.61 (Table 1). Number of people per household is 4.18 and the number of household labors is 3.15, indicating 
that almost three out of four members are able to render income for the household by working in the rice farming or somewhere else.

The average productivity of the households is about 1.78 tons of rice per $1,000 \mathrm{~m}^{2}$, with a SD of 1.24 tons, implying that productivity varies across farmers depending on their resource endowments. The average cultivation land area shows much difference among the households since the SD of total cultivation land area is $17,120 \mathrm{~m}^{2}$, relatively large as compared to its mean of $24,650 \mathrm{~m}^{2}$. There are farmers who rented land to produce rice, although the area of hired land is relatively small as compared to the total land area cultivated by the households (approximately 3.3 per cent).

Educational attainment of the household heads is really low, with an average schooling of 6.85 years, given a SD of 3.21 years (Table 2). The average schooling of member 2 is almost the same as that of household heads since they are wives or husbands and possibly have nearly identical age with the former. This finding reflects the undesirable educational condition for that generation (i.e. lack of schools, difficulty to travel to schools because of bad transport means in rural areas and low income). Educational attainment signifies the ability to acquire technological advances and market information (especially price). Thus, such a low level of education adversely affects agricultural output. It is interesting that the average schooling of members 3, 4 and 5, who are mainly children in the family, increases significantly as compared to that of their parents. This phenomenon shows the appreciation of education by the households, so they have attempted to get better education for their children by trying hard to send them to schools, junior colleges and universities, not only to show up but expect that education would bring a certain economic value and higher income for the family.

Table 3 shows that the highest cost of rice production of the households is of fertilizer, amounting to VND million 1.60 per $1,000 \mathrm{~m}^{2}$ and about 2.3 times of what is spent on labors, which is the second highest cost with an average of VND million 0.71 per $1,000 \mathrm{~m}^{2}$ and a SD of VND million 0.57 . Fertilizer accounts for the highest cost of rice production because the soil in the MRD has downgraded enormously in the course of time due to the triple cropping and the overuse of chemicals that deprives the soil of fertility (Cao and Le, 2020). Labor cost is high because of the lack of rural labors that creates short supplies of labors, thus substantially

\begin{tabular}{lrrrr}
\hline Criteria & Mean & SD & Min & Max \\
\hline Age of household head (years) & 51.56 & 10.61 & 23.00 & 83.00 \\
Number of people per household & 4.18 & 1.25 & 1.00 & 9.00 \\
Number of labors per household (people) & 3.15 & 1.05 & 0 & 6.00 \\
Productivity (tons of rice per 1,000 m²) & 1.78 & 1.24 & 0.19 & 2.50 \\
Total cultivated land area $\left(1,000 \mathrm{~m}^{2}\right)$ & 24.65 & 17.12 & 1.00 & 100.00 \\
Owned cultivated land area $\left(1,000 \mathrm{~m}^{2}\right)$ & 23.83 & 16.82 & 0 & 100.00 \\
Rented cultivated land $\left(1,000 \mathrm{~m}^{2}\right)$ & 0.82 & 0.48 & 0 & 60.00
\end{tabular}

Source(s): The author's survey (2018)

Economic role of education in agriculture

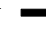


JED 23,1

\section{4}

pushing up wages of hired labors. Pesticide costs the households as much as VND million 0.67 per $1,000 \mathrm{~m}^{2}$ (Table 3 ), showing that they have cared very much about protecting rice plants from recurrences of serious diseases, especially in the imminent presence of climate change that makes weather largely unpredictable. Cost for herbicide seems to be not very important for the households (about VND million 0.24 per $1,000 \mathrm{~m}^{2}$ ).

\subsection{Impact of education on output of rice farmers}

6.2.1 Constant coefficient models. This sub-section presents the estimates of two constant coefficient models specified above so as to assess the impact of education on output of rice farming households in the MRD. Column 2 of Table 4 divulges the estimated coefficients of the augmented linear model using the OLS estimator while Column 3 shows those of the partially nonlinear model using Robinson's (1988) double residual estimator.

The results in these two columns are quite consistent, showing that education does not affect rice output if standing alone since the two coefficients associated with the education variable $\left(\mathrm{edu}_{i}\right)$ are not statistically significant. This is because education is not a conventional input but rather a contextual factor that contributes to triggering the marginal productivity of other inputs (Wouterse and Badian, 2019). Column 2 of Table 4 reveals that farm size has a positive relationship with rice output, which is attributed to the advantage in adopting advanced technology, obtaining increasing returns to scale and fetching market power that is normally associated with farms of larger size (Deininger and Byerlee, 2012). In addition,

Table 3.

Input cost of rice production (VND million per $1,000 \mathrm{~m}^{2}$ )

\begin{tabular}{lcccr}
\hline Criteria & Mean & SD & Min & Max \\
\hline Fertilizer & 1.60 & 1.66 & 0 & 5.50 \\
Labor & 0.71 & 0.57 & 0 & 8.00 \\
Pesticide & 0.67 & 0.78 & 0 & 10.00 \\
Seed & 0.55 & 1.65 & 0 & 7.74 \\
Herbicide & 0.24 & 0.45 & 0 & \\
Source(s): The authors' survey (2018) & & &
\end{tabular}

\section{Variables \\ Dependent variable: Log of rice output}

(1)

\begin{tabular}{ll}
\hline Seed $_{i}$ & Log of seed cost \\
Fertilizer $_{i}$ & Log of fertilizer cost \\
Pesticide $_{i}$ & Log of pesticide cost \\
Herbicide $_{i}$ & Log of herbicide cost \\
Labor $_{i}$ & Log of labor cost \\
Farmsize $_{i}$ & Log of farm size \\
edu $_{i}$ & Years of schooling of household head \\
Constant $C$ & \\
Number of observation $(N)$ \\
Prob $>F$ & \\
$R$-squared & \\
Adj. $R$-squared
\end{tabular}

Table 4.

Estimation results of constant coefficient models

Note(s): (*), $(* *)$ and $(* * *)$ designate statistical significance at the 10,5 and $1 \%$, respectively Source(s): The author's survey (2018)
Augmented linear model Partially nonlinear model (2)

(3)

$-0.1323^{* * * *}(-3.84)$
$0.2143^{* * *}(8.20)$
$0.0162(0.74)$
$0.0065(0.30)$
$-0.1941^{* * *}(-6.18)$
$1.0602 * * *(41.02)$
$0.0263(1.58)$
$-7.0622(-30.34)$
901
0.000
0.8159
0.8145
0.3948
$-0.1007 * * *(-3.25)$
$0.1921^{* * * *}(7.68)$
0.0165 (0.77)
$-0.0187(-0.89)$
-0.2013 *** $(-6.67)$
0.0268 (1.67)

901

0.1612

0.1556

0.3742 
owners of larger farms find it easier to access credit and obtain inputs of better quality, especially where credit and factor markets malfunction. This relationship is also confirmed by Figure 1 resulted from Robinson's (1988) double residual estimator used to estimate the partially nonlinear model in Column 3 of Table 4.

It is obvious that seed $\mathrm{d}_{i}$ has a significantly negative coefficient at $1 \%$ for the augmented linear model in Column 2 and for the partially nonlinear model in Column 3 as well, meaning that the more seed is used, the lower output will be. This finding is understandable since seed is vital to rice yield. If not using the right amount of seed with proper quality, there exists a risk of bad harvest that is very costly to make it up because seed of low quality often sprouts and grows poorly. Therefore, farmers have tended to overuse this input for a fear of bad harvest that will substantially deprive them of income, resulting in such a high density that adversely affects rice yield (Cao and Le, 2020).

The coefficients of fertilizer ${ }_{i}$ are positive and significant at $1 \%$ for both augmented linear model and partially nonlinear one, indicating that the quality of soil of rice fields in the MRD has deteriorated enormously because of the triple cropping pursued by rice farming households. This behavior requires a continuous nutrient supplement by applying more chemical fertilizers in order to maintain or trigger output. However, pesticide ${ }_{i}$ and herbicide ${ }_{i}$ also have no significant coefficients for both augmented linear and partially nonlinear models, asserting that those inputs do not play any role in triggering rice output. This result stems from the fact that rice farmers tend to use an amount of those toxic chemicals that well exceeds the amount prescribed by experts, which is adamant since it has deeply rooted in their mind. In addition to this, there is also the so-called "household effect" (Aida, 2018), where farmers communicate about their pest and weed management strategies or where farmers who lack information look to the application pattern of neighbors for direction, which results in inappropriate use of chemicals.

Finally, labor ${ }_{i}$ has a negative coefficient that is significant at $1 \%$ for both augmented linear model and partially nonlinear model. Indeed, the more labors households use, the more they have to hire because there has been a lack of labors in rural areas of the MRD. When using more hired labors, households face a more serious problem of moral hazard (i.e. shirking and cheating) often observed from hired labors since wages are normally predetermined while their work effort is not be fully observable, verifiable and enforceable owing to information imperfection.

6.2.2 Varied coefficient models. One may conclude from the results shown in Table 4 that education plays no role in enhancing rice output. This conclusion may deceive since the

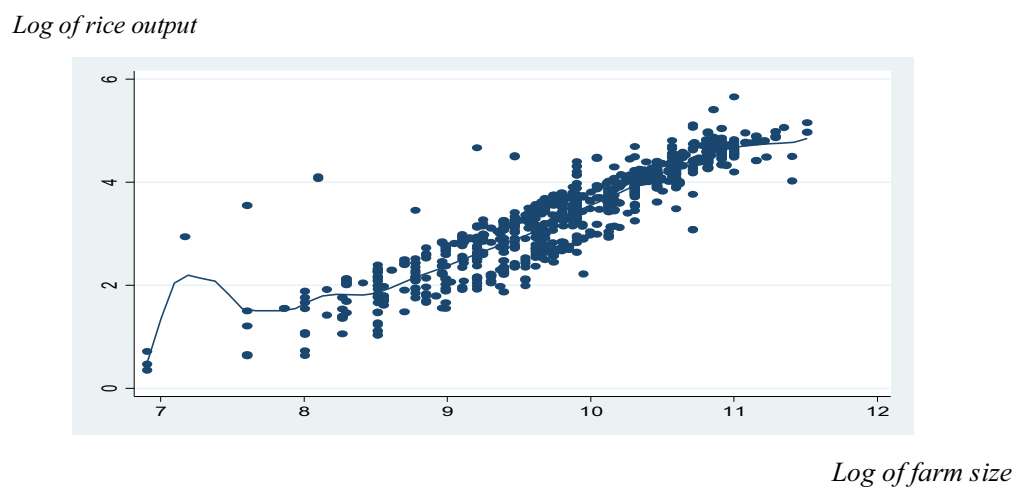

Source(s): The author's survey (2018)
Economic role of education in agriculture
Figure 1.

Positive relationship between farm size and rice output 
JED

23,1

56

models that have been applied are probably inappropriate in the sense that the coefficient of farm size variable (farmsize), i.e. the factor testifying the education-backed decisions of farmers over their farms, does not vary with educational attainment. Thus, we have to allow the coefficient associated with farmsize $i_{i}$ to vary with education variable $\left(e^{2} u_{i}\right)$ across households as specified in Eqn (4). Estimates for Eqn (4) using OLS estimator is presented in Table 5.

Table 5 shows that the coefficients of $\operatorname{seed}_{i}$, fertilizer $i$, pesticide $_{i}$, herbicide ${ }_{i}$ and labor $_{i}$ have the same signs and almost the same magnitudes as those presented in Table 4 for the constant coefficient models, confirming the robustness of the models and the data used in this paper. The coefficient of the interaction term between farm size variable and education variable (farmsize $e_{i} \times$ edu $_{i}$ ) is positive and significant at $1 \%$, in line with the theoretical expectation that $\partial^{2} y_{i} / \partial\left(\right.$ farmsize $\left._{i}\right) \partial\left(\right.$ edu $\left._{i}\right)=0.0074>0$. In other words, this finding ascertains the desirable role of education to agricultural output or education has an economic value and hence deserves a good deal of investment from both the government and households. Since it is already confirmed the positive relationship between farm size and output, we do not show the estimate of Eqn (5) where the form of the relationship is not specified a priori (partially nonlinear model).

\section{Conclusion}

Reality has witnessed that rural households in developing countries invest quite a good deal of limited resources in attaining better education. This behavior has attracted a lot of attention of researchers in testing for the economic role of education to agricultural output. By the same token, this paper is conducted using a primary dataset of 901 rice farming households randomly selected out of ten provinces and city in the MRD of Vietnam.

In the constant coefficient models, some of the conventional inputs have proved their effects on rice output while the others do not. Meanwhile, the estimates of these models also show a positive relationship between farm size and output as found by a number of previous studies. However, those models do not show any effect of education (proxied by the number of schooling years of household heads) on rice output. This result may deceive because these models fail to describe the right mechanism through which education affects rice output. Thus, the varied coefficient models is used in this paper to tackle the problem.

\begin{tabular}{|c|c|c|}
\hline \multicolumn{2}{|r|}{ Dependent variable: Log of rice output } & \multirow{2}{*}{$\begin{array}{c}\text { Estimated coefficients } \\
(2) \\
-0.1296^{* * *}(-3.81)\end{array}$} \\
\hline $\operatorname{Seed}_{i}$ & Log of seed cost & \\
\hline Fertilizer $_{i}$ & Log of fertilizer cost & $0.2129 * * *(8.24)$ \\
\hline Pesticide $_{i}$ & Log of pesticide cost & $0.0226(1.01)$ \\
\hline Herbicide $_{i}$ & Log of herbicide cost & $-0.0012(-0.06)$ \\
\hline Labor $_{i}$ & Log of labor cost & $-0.1889 * * *(-6.08)$ \\
\hline Farmsize $_{i}$ & Log of farm size & $1.0377 * * *(39.92)$ \\
\hline $\mathrm{Edu}_{i}$ & Years of schooling of household head & $0.0168(1.01)$ \\
\hline Farmsize $_{i} \times$ edu $_{i}$ & Interaction between log of farm size and education of household head & $0.0074 * * *(4.69)$ \\
\hline Constant $C$ & & $-6.9762 * * *(-30.22)$ \\
\hline \multicolumn{2}{|c|}{ Number of observation $(N)$} & 901 \\
\hline \multicolumn{2}{|l|}{ Prob $>F$} & 0.000 \\
\hline \multicolumn{2}{|l|}{$R$-squared } & 0.8201 \\
\hline \multicolumn{2}{|l|}{ Adj. $R$-squared } & 0.8185 \\
\hline \multicolumn{2}{|l|}{ Root MSE } & 0.3905 \\
\hline \multicolumn{3}{|c|}{$\begin{array}{l}\text { Note(s): }(*),(* *) \text { and }(* * *) \text { designate statistical significance at the } 10,5 \text { and } 1 \% \text {, respectively } \\
\text { Source(s): The author's survey }(2018)\end{array}$} \\
\hline
\end{tabular}

Table 5.

Estimation results of the varied coefficient model

Source(s): The author's survey (2018) 
Estimates of the varied coefficient model shows almost the same results for the impact of the conventional inputs (i.e. seed, fertilizer, pesticide, herbicide and labor) on rice output, which ascertains the robustness of the empirical results. Again, the model reveals the positive relationship between farm size and rice output. The positive and significant coefficient of the interaction term between farm size variable (farmsize $\left.{ }_{i}\right)$ and education variable $\left(\mathrm{edu}_{i}\right)$ divulges the economic value of education since it is able to improve output and thus income of rice farming households. This finding would mean that triggering public and private investments in education will bring better benefits for households in particular and people in general, which may contribute to economic growth and rice output in the long term.

\section{References}

Afriat, S.N. (1972), "Efficiency estimation of production functions", International Economic Review, Vol. 13 No. 3, pp. 568-598.

Aida, T. (2018), "Neighbourhood effects in pesticide use: evidence from the rural Philippines", Journal of Agricultural Economics, Vol. 69 No. 1, pp. 163-181.

Ali, D.A. and Deininger, K. (2015), "Is there a farm size-productivity relationship in african agriculture? Evidence from Rwanda", Land Economics, Vol. 91 No. 2, pp. 317-343.

Asadullah, M.N. and Rahman, S. (2009), "Farm productivity and efficiency in rural Bangladesh: the role of education revisited", Applied Economics, Vol. 41 No. 1, pp. 17-33.

Asfaw, A. and Admassie, A. (2004), "The role of education on the adoption of chemical fertilizer under different socioeconomic environments in Ethiopia”, Agricultural Economics, Vol. 30 No. 3, pp. 215-228.

Barrett, C., Bellemare, M.F. and Hou, J.Y. (2010), "Reconsidering conventional explanations of the inverse productivity-size relationship”, World Development, Vol. 38 No. 1, pp. 88-97.

Barro, R. and Lee, J.W. (2010), A New Data Set of Educational Attainment in the World, 1950-2010, National Bureau of Economic Research, Working Paper, Cambridge, MA.

Bhalla, S.S. and Roy, P. (1988), "Mis-specification in farm productivity analysis: the role of land quality", Oxford Economic Papers, Vol. 40, pp. 55-73.

Brunjes, J. and Diez, J.R. (2016), “Obtaining non-farm wage employment in rural Vietnam”, Asia Pacific Viewpoint, Vol. 57 No. 2, pp. 263-279.

Cao, V.H. and Le, K.N. (2020), "Impact of credit rationing on capital allocated to inputs used by rice farmers in the Mekong River Delta, Vietnam", Journal of Economics and Development, Vol. 22 No. 1, pp. 47-60.

Carletto, C., Savastano, S. and Zezza, A. (2013), "Fact or artifact: the impact of measurement errors on the farm size - productivity relationship", Journal of Development Economics, Vol. 103, pp. 254-261.

Croppenstedt, A. and Demeke, M. (1997), "An empirical study of cereal crop production and technical efficiency of private farmers in Ethiopia: a mixed fixed-random coefficient approach", Applied Economics, Vol. 29 No. 9, pp. 1217-1226.

Deininger, K. and Byerlee, D. (2012), "The rise of large farms in land abundant countries: do they have a future?", World Development, Vol. 40 No. 4, pp. 701-714.

DeSilva, S., Evenson, R.E. and Kimhi, A. (2006), "Labor supervision and institutional conditions: evidence from bicol rice farms", American Journal of Agricultural Economics, Vol. 88 No. 4, pp. 851-865.

Escobal, J. and Laszlo, S. (2008), "Measurement error in access to markets", Oxford Bulletin of Economics and Statistics, Vol. 70 No. 2, pp. 209-243.

Fielke, S.J. and Bardsley, D.K. (2014), "The importance of farmer education in south Australia", Land Use Policy, No. 39, pp. 301-312. 
JED

23,1

58

Foster, A.D. and Rosenzweig, M.R. (1994), "A test for moral hazard in the labor market: contractual arrangements, effort, and health", Review of Economics and Statistics, Vol. 76 No. 2, pp. 213-227.

Hildreth, C. and Houck, J. (1968), "Estimators for a linear model with random coefficients", Journal of the American Statistical Association, Vol. 63 No. 322, pp. 584-595.

Knight, J., Weir, S. and Woldehanna, T. (2003), "The role of education in facilitating risk-taking and innovation in agriculture", Journal of Development Studies, Vol. 39 No. 6, pp. 1-22.

Larson, D.F., Otsuka, K., Matsumoto, T. and Kilic, T. (2014), "Should african rural development strategies depend on smallholder farms? An exploration of the inverse - productivity hypothesis", Agricultural Economics, Vol. 45, pp. 355-367.

Lin, J.Y. (1991), "Education and innovation adoption in agriculture: evidence from hybrid rice in China", American Journal of Agricultural Economics, Vol. 73 No. 3, pp. 713-723.

Muyanga, M. and Jayne, T.S. (2019), "Revisiting the farm size-productivity relationship based on a relatively wide range of farm size: evidence from Kenya", American Journal of Agricultural Economics, Vol. 101 No. 4, pp. 1140-1163.

Pham, D.N.T. and Tran, T.T.H. (2015), "Rethinking education and training in Vietnam rural areas", US-China Education Review, Vol. 5 No. 6, pp. 398-405.

Reimers, M. and Klasen, S. (2013), "Revisiting the role of education for agricultural productivity", American Journal of Agricultural Economics, Vol. 95 No. 1, pp. 131-152.

Robinson, P.M. (1988), "Root-N-Consistent semiparametric regression", Econometrica, Vol. 36 No. 4, pp. 931-954.

Sheng, Y., Ding, J. and Huang, J. (2019), "The relationship between farm size and productivity in agriculture: evidence from maize production in Northern China", American Journal of Agricultural Economics, Vol. 101 No. 3, pp. 790-806.

Swamy, P.A.V.B. and Tavlas, G.S. (1995), "Random coefficient models: theory and application", Journal of Economic Surveys, Vol. 9 No. 2, pp. 165-196.

Taylor, J.E. and Yunez-Naude, A. (2000), "The returns from schooling in a diversified rural economy", American Journal of Agricultural Economics, Vol. 82, pp. 287-297.

Varian, H.R. (1984), "The nonparametric approach to production analysis", Econometrica, Vol. 52 No. 3, pp. 579-597.

Vollrath, D. (2007), "Land distribution and international agricultural productivity", American Journal of Agricultural Economics, Vol. 89 No. 1, pp. 202-216.

Weir, S. and Knight, J. (2004), "Externality effects of education: dynamics of the adoption and diffusion on an innovation in rural Ethiopia”, Economic Development and Cultural Change, Vol. 53 No. 1, pp. 93-113.

Wouterse, F. (2016), "Can human capital variables Be technology changing? An empirical test for rural households in Burkina Faso", Journal of Productivity Analysis, Vol. 45, pp. 157-172.

Wouterse, F. and Badiane, O. (2019), "The role of health, experience, and educational attainment in agricultural production: evidence from smallholders in Burkina Faso", Agricultural Economics, Vol. 50, pp. 421-434.

\section{Corresponding author}

Le Khuong Ninh can be contacted at: lekhuongninh@gmail.com

For instructions on how to order reprints of this article, please visit our website:

www.emeraldgrouppublishing.com/licensing/reprints.htm

Or contact us for further details: permissions@emeraldinsight.com 